\title{
POTENTIOMETRIC ION- AND BIO-SELECTIVE ELECTRODES BASED ON ASYMMETRIC CELLULOSE ACETATE MEMBRANES
}

\author{
Geun Sig Cha and Mark E. MeyerhofF* \\ Department of Chemistry, The University of Michigan, Ann Arbor, MI 48109-1055, U.S.A.
}

(Received 6 May 1988. Accepted 14 July 1988)

\begin{abstract}
Summary-The potentiometric response properties of ammonium-, carbonate-, and proton-selective electrodes prepared by incorporating appropriate neutral carriers within novel asymmetric cellulose acetate membranes are reported. The membranes are formed by first casting a thin layer of cellulose triacetate without carrier, hydrolyzing one side of this film with base, and then on the other side casting a second layer of cellulose triacetate containing the membrane active components. The resulting asymmetric ion-selective membranes function equivalently, in terms of selectivity and response slopes, to non-asymmetric cellulose triacetate membranes and conventional poly(vinyl chloride)-based membranes. The hydrolyzed surface of the asymmetric membranes can be activated in aqueous solution with carbonyldiimidazole for the direct immobilization of proteins on the surface of the membranes, without loss in potentiometric ion-response. As an example, the immobilization of urease on the surfaces of ammonium- and carbonate-selective membranes yields potentiometric bio-selective urea-probes with desirable dynamic response properties.
\end{abstract}

Over the last two decades, a variety of potentiometric ion- and gas-selective membrane electrodes have been used as detection elements to prepare novel bioselective electrodes. ${ }^{1-6}$ Such bio-electrodes are generally fabricated by immobilizing appropriate biological species (e.g., enzymes, intact cells, antibodies, etc.) in a layer adjacent to the sensing membrane of the electrodes. Often, this process involves covalently attaching the bioreagents to a secondary membrane which can then be mounted on the ion- or gas-sensing membrane. Alternatively, the bioreagents can be crosslinked or entrapped within a gel layer adjacent to the sensing surface. However, the adhesiveness, thickness, and enzyme-loading factor of these layers are critical to the performance (including response times and stability) of the resulting devices. ${ }^{4-8}$ In this paper, we report on the development of a new type of ion-selective polymeric membrane to which enzymes and other biospecies can be covalently attached directly, for the purpose of preparing potentiometric bio-selective electrodes with improved response properties.

Interest in using solvent/polymeric membrane electrodes as the sensors in bio-electrodes arises from the high ion-selectivities, rapid response times (compared to gas-sensors), and ease of fabrication (for disposable sensors) associated with these devices. Traditionally, the most analytically useful membranes are prepared by incorporating electrically neutral carrier molecules into plasticized poly(vinyl chloride) (PVC) membranes. ${ }^{9-12}$ Direct covalent attachment of bio-

\footnotetext{
*Author to whom all correspondence should be addressed.
}

reagents to the surfaces of such membranes would require the incorporation of functional groups, either in the form of membrane-soluble lipophilic additives or derivatized polymeric materials. However, such changes in membrane composition can result in loss of potentiometric ion-selectivity. ${ }^{12,13}$ Recently, various groups have demonstrated that carboxylatedPVC can be used as a replacement for regular PVC without decreasing the selectivity of neutral carrierbased membranes. ${ }^{14-16}$ Moreover, certain enzymes or crosslinked enzyme gels have been shown to adhere tightly, albeit non-covalently, to the surfaces of these carboxylated membranes. ${ }^{17,18}$

One of our long-term goals has been to devise methods for covalent attachment of very thin films, even monolayers, of bioreagents directly to the surface of polymeric ion-selective electrodes (ISEs) without altering the ion-response of the electrodes. Although some success has been achieved by using aminated-PVC as a membrane matrix, ${ }^{16}$ we now describe a new approach involving asymmetric plasticized cellulose acetate membranes. Though ISEs for calcium, based on cellulose acetate membranes, have been described previously, ${ }^{19}$ the use of cellulose acetate in the fabrication of solvent/polymeric electrodes is not widespread, nor have there been any attempts to use such membranes to prepare biosensors.

In the proposed method, one side (the sample side) of a thin layer of cellulose triacetate cast without active membrane components is hydrolyzed with base. A second layer of cellulose acetate containing the appropriate neutral carrier and plasticizer is then cast on the other side of the cellulose triacetate film 

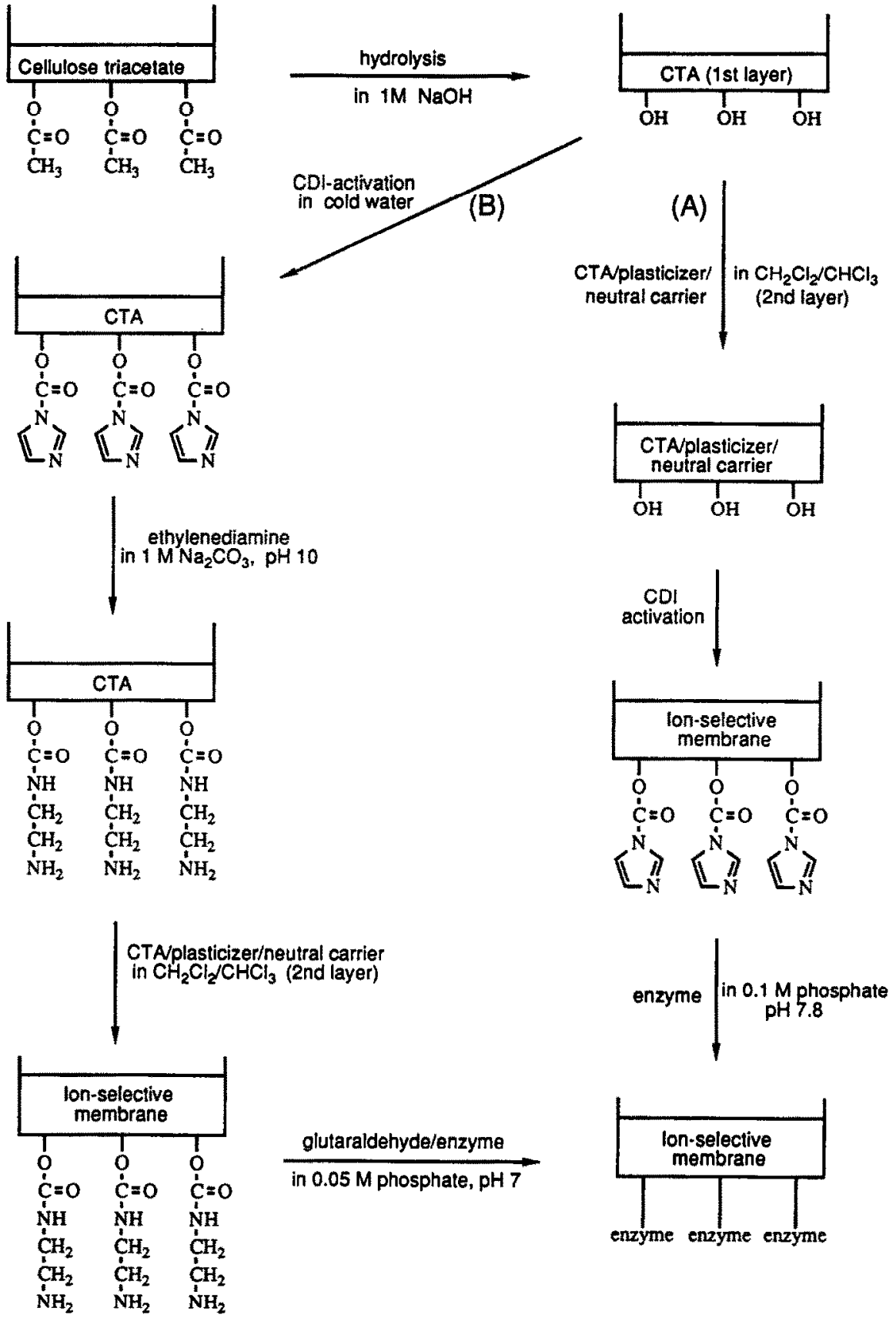

Fig. 1. General schemes used to prepare enzyme-immobilized asymmetric ion-selective cellulose triacetate membranes; (A) the direct CDI method for the hydroxylated membrane; (B) the glutaraldehyde method for aminated membrane.

(see Fig. 1). Ammonium-, carbonate-, and $\mathrm{pH}$ selective membranes serve as models for these investigations. These membranes are prepared with nonactin, trifluoroacetyl-p-butylbenzene, and tridodecylamine, respectively. The hydroxyl groups on the hydrolyzed surface of the membrane can be activated in aqueous solution with carbonyldiimidazole (CDI). Three different methods can then be used to attach enzymes or other proteins directly to the surface of the ion-selective electrodes. The relative advantages and disadvantages of each attachment method are demonstrated by evaluating the performance of a number of urea-selective electrodes prepared with immobilized urease.

\section{EXPERIMENTAL}

\section{Apparatus}

The external reference electrode was a Fisher doublejunction $\mathrm{Ag} / \mathrm{AgCl}$ electrode with an outer cracked-bead junction. All membranes were mounted in Phillips electrode 
bodies (IS-561) (Glasblaserei Möller, Zurich). For potentiometric measurements of ion-responses, the ISEs and external reference electrode were connected through highimpedance amplifiers to a Zenith Z-100 PC computer equipped with a Data Translations (DT280I) analog-todigital converter. The potentiometric response of enzyme electrodes was measured with a Fisher Model $620 \mathrm{pH} / \mathrm{mV}$ meter and recorded on a Fisher Recordall Series 5000 strip-chart recorder.

\section{Reagents}

Cellulose triacetate (CTA), 1,1'-carbonyldiimidazole (CDI), bis(2-ethylhexyl) sebacate and nonactin were obtained from Fluka (Ronkonkoma, NY), and dipenty] phthalate, tridodecylamine, and sodium tetraphenylborate were products of Eastman Kodak (Rochester, NY). Trifluoroacetyl-p-butylbenzene (TFABB) was purchased from Specialty Organics, Inc. (Irwindale, CA), tridodecylmethylammonium chloride from Polysciences, Inc. (Warrington, PA), 1,1,2,2,-tetrachloroethane from Aldrich Chemical Co. (Milwaukee, WI) and urease (Type VII, from jack beans) from Sigma Chemical Co. (St. Louis, MO).

All other chemicals used were analytical-reagent grade. Standard solutions and buffers were prepared with demineralized water.

\section{Preparation of various ion-and bio-selective membranes}

Figure 1 summarizes the schemes used to prepare asymmetric jon-selective CTA membranes with immobilized enzymes. Details of these methods are described below.

Hydroxylated or aminated cellulose triacetate membranes. A thin membrane $(e . g ., 50 \mu \mathrm{m})$ was prepared by dissolving $100 \mathrm{mg}$ of CTA in a mixed solvent $(1.5 \mathrm{ml}$ of methylene chloride, $0.5 \mathrm{ml}$ of chloroform and $0.5 \mathrm{ml}$ of 1,1,2,2-tetrachloroethane) and casting the mixture in a 36-mm (i.d.) glass ring placed on a glass plate. The solvent was allowed to evaporate for 2 days. Acetyl groups on the bottom side of the membrane were then hydrolyzed by floating the membrane on $1 M$ sodium hydroxide for $4.5 \mathrm{hr}$. After washing with distilled water, the membrane was air-dried.

To introduce amino groups onto the membrane, the hydroxyl groups (resulting from the hydrolysis procedure) of the membrane were activated with CDI by immersing the bottom side of the membrane in $20 \mathrm{ml}$ of cold distilled water $\left(4^{\circ}\right)$ and adding an excess of 1,1'-carbonyldiimidazole (about $50 \mathrm{mg}$ ) in $10-15 \mathrm{mg}$ portions over a $15-\mathrm{min}$ period. After brief washing with cold water, the membrane was immersed in a $12.5 \%(\mathrm{w} / \mathrm{v})$ ethylenediamine solution in $1 \mathrm{M}$ sodium carbonate buffer ( $\mathrm{pH} \mathrm{10)}$ for $3 \mathrm{hr}$ at room temperature. After extensive washing with water, the membrane was air-dried.

Asymmetric cellulose triacetate ion-selective membranes. The hydroxylated or aminated membranes were placed on a glass plate with the derivatized surface face down. The unmodified upper surface of the membrane was then pretreated for 30 min with $1.2 \mathrm{ml}$ of methylene chloride inside a 22-mm (i.d.) glass ring placed on top of the membrane. During this period, the membrane was kept inside a desiccator to reduce evaporation of the methylene chloride. A mixture containing the appropriate amounts of membrane components, depending on which ion-selective membrane was being prepared, was then put inside the glass ring. In all cases, $35 \mathrm{mg}$ of CTA was utilized with a mixed solvent of $0.8 \mathrm{ml}$ of methylene chloride and $0.8 \mathrm{ml}$ of chloroform. Additional components (i.e., plasticizer, neutral carrier, or lipophilic additive) for each ion-selective system were as follows: $6 \mathrm{mg}$ of nonactin and $120 \mu \mathrm{l}$ of dipentyl phthalate for $\mathrm{NH}_{4}^{+} ; 100 \mu \mathrm{l}$ of bis(2-ethylhexyl) sebacate, $8.3 \mathrm{mg}$ of trifluoroacetyl-p-butylbenzene, and $3.1 \mathrm{mg}$ of tridodecylmethylammonium chloride for $\mathrm{CO}_{3}^{2-} ; 155 \mu 1$ of dipentyl phthalate, $20 \mathrm{mg}$ of tridodecylamine, and $12 \mathrm{mg}$ of sodium tetraphenylborate for $\mathrm{H}^{+}$. Again, the mixed solvent was allowed to evaporate very slowly by keeping the membrane in a vacuum desiccator with the tap only slightly open. In this manner, the two membrane layers were fused into a single asymmetric membrane.

Smaller disks were punched from these membranes and mounted in Phillips electrode bodies with the derivatized side facing the outer sample solution. The inner filling solution varied, depending on which ion-selective membrane was being evaluated $\left(0.1 M \quad \mathrm{NH}_{4} \mathrm{Cl}\right.$ for $\mathrm{NH}_{4}^{+}$-selective membranes; $0.1 M \mathrm{NaH}_{2} \mathrm{PO}_{4} / 0.1 M \mathrm{Na}_{2} \mathrm{HPO}_{4} / 0.01 M \mathrm{NaCl}$ for $\mathrm{CO}_{3}^{2-}$-selective membranes; $0.02 M \quad \mathrm{NaH}_{2} \mathrm{PO}_{4} / 0.03 M$ $\mathrm{Na}_{2} \mathrm{HPO}_{4} / 0.015 M \mathrm{NaCl}$ for $\mathrm{H}^{+}$-selective membranes). All potential measurements were made at room temperature, with $200 \mathrm{ml}$ of sample solution, after conditioning the membranes overnight.

Direct immobilization of urease on hydroxylated asymmetric ion-selective membranes. Hydroxylated membranes mounted in electrode bodies were immersed in cold water and activated by adding an excess of 1,1'-carbonyldiimidazole as described above for amination. After brief washing of the membranes with cold water, $10 \mu \mathrm{l}$ of urease solution [1 mg of urease $(615 \mu$ mole units $/ \mathrm{mg})$ per $10 \mu \mathrm{l}$ of $0.1 M$ sodium phosphate $/ 0.5 M$ sodium chloride buffer $(\mathrm{pH}$ 7.8)] were applied directly to the surface of the membranes. The reaction was allowed to continue for $12 \mathrm{hr}$ at $4^{\circ}$. The membranes were thoroughly washed with $0.05 \mathrm{M}$ Tris- $\mathrm{HCl}$ buffer $(\mathrm{pH} 7.2)$ to remove unbound enzyme and block unreacted active groups.

Immobilization of urease on aminated ion-selective membranes. For the one-step glutaraldehyde method, $10 \mu 1$ of urease solution ( $1 \mathrm{mg}$ of urease per $10 \mu 1$ of $0.05 \mathrm{M}$ sodium phosphate buffer, $\mathrm{pH} 7.0$ ) and $4.5 \mu 1$ of $2.5 \%$ glutaraldehyde solution in the same buffer were sequentially applied to the aminated surface of the ion-selective membrane mounted in an electrode body.

For the two-step glutaraldehyde method, the membrane was first activated in $2.5 \%$ glutaraldehyde solution for 5 min. After a brief washing of the membrane, $10 \mu 1$ of urease solution were applied directly to its surface.

After the coupling reactions for $12 \mathrm{hr}$ at $4^{\circ}$ the membranes were thoroughly washed with $\mathrm{Tris}-\mathrm{HCl}$ buffer to remove any excess of glutaraldehyde and unbound enzyme and stored in buffer at $4^{\circ}$ when not in use.

\section{Evaluating potentiometric response of ion-selective and enzyme electrodes}

The potentiometric responses of various CTA membranes to ions, and corresponding enzyme electrodes to urea, were evaluated with different background electrolytes, depending on which ion-selective system was being examined $(0.05 M$ Tris- $\mathrm{HCl}, \mathrm{pH} 7.2$ for $\mathrm{NH}_{4}^{+}$or urea response with an $\mathrm{NH}_{4}^{+}$-selective membrane; $0.1 M$ Tris- $\mathrm{H}_{2} \mathrm{SO}_{4}, \mathrm{pH} 8.75$ for $\mathrm{CO}_{3}^{2-}$ response or $\mathrm{pH} 8.4$ for urea response with a $\mathrm{CO}_{3}^{2-}$-selective membrane; $11.4 \mathrm{~m} M$ boric acid $/ 6.7 \mathrm{mM}$ citric acid $/ 10.0 \mathrm{mM} \mathrm{NaH} \mathrm{PO}_{4}$ for $\mathrm{pH}$ response, or $0.001 M$ Tris$\mathrm{HCl} / 0.1 M \mathrm{NaCl}$, pH 7.0 for urea response with a protonselective membrane). The calibration plots were obtained from additions of standard inorganic salt or urea solutions to $200 \mathrm{ml}$ of background electrolyte at room temperature. The solutions were magnetically stirred throughout and the steady-state or equilibrium potentials were recorded

\section{RESULTS AND DISCUSSION}

A scanning electron micrograph of the crosssection of a typical asymmetric ion-selective cellulose acetate membrane is shown in Fig. 2. It can be seen that the membrane consists of two fused layers; a dense ion-selective plasticized layer covered with a thin modified layer (upper layer). The hydrolyzed 


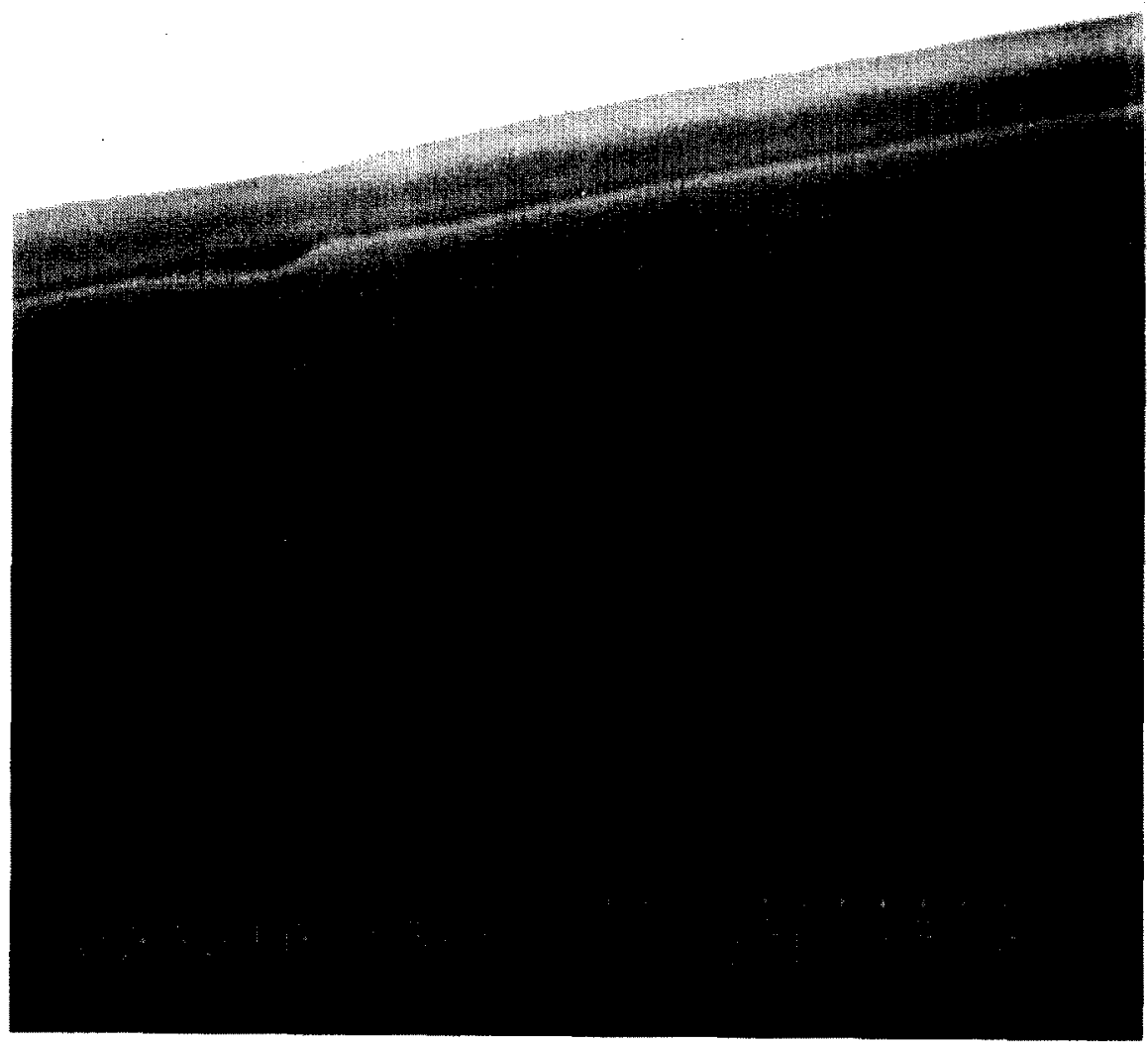

Fig. 2. Scanning electron micrograph showing the cross-section of a typical asymmetric ion-selective cellulose triacetate membrane.

hydrophilic thin layer (approximately $5 \mu \mathrm{m}$ in thickness) is immiscible with organic solvents (plasticizers) and can be used for covalent immobilization of biomolecules such as cnzymes, by CDI-activation methods. Although the initial studies were focused on the direct hydrolysis of homogeneous plasticized CTA membranes, this approach was abandoned since a much longer period (more than 5 days) is required to produce a sufficient number of surface hydroxyl groups and the critical membrane active components (e.g., nonactin) may be degraded during this hydrolysis period.

Previously, organic solvents (e.g., dioxan or acetone) have been used for the CDI-activation of the hydroxylic polysaccharide matrices (e.g., crosslinked agarose or dextran, cellulose, etc.). ${ }^{20-22} \mathrm{Un}$ fortunately, these organic solvents will dissolve the membrane active components (i.e., neutral carrier or plasticizer) and may, in fact, deform the ion-selective membranes. Therefore, it was critical to find an activation method which would work in aqueous solutions. In subsequent experimenı, we found that the CDI-activation can be done in aqueous solution provided that a relatively large amount of $\mathrm{CDI}$ is used. Indeed, after coupling of ethylenediamine to the hydrolyzed surface through aqueous CDI-activation (as described in the Experimental section), treatment of the membrane with trinitrobenzenesulfonate reagent (TNBS) ${ }^{23}$ gave an immediate orange-red color, indicating that the surface of the membrane had been aminated to a significant degree. Such an experiment provided clear evidence that the hydrophilic layer of the asymmetric membranes could be derivatized and used as a site for later attachment of biomolecules. 


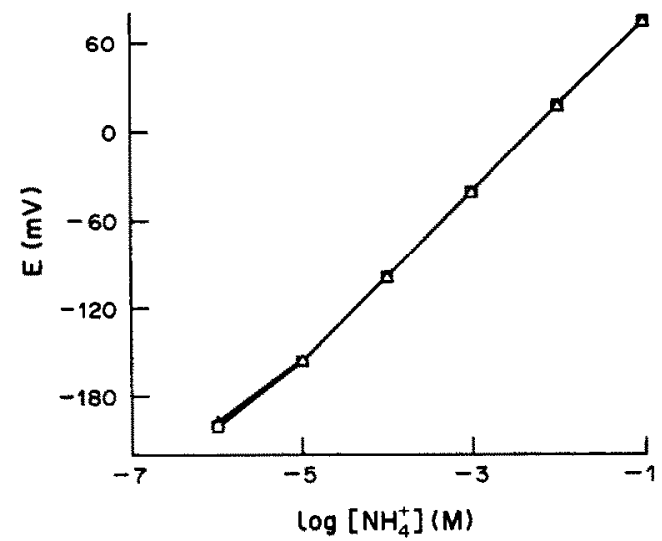

Fig. 3. Potentiometric ammonium response of various cellulose triacetate-based membranes doped with nonactin: $(\Delta)$ hydroxylated asymmetric membrane; $(x)$ aminated asymmetric membrane; ( $\square$ ) unmodified cellulose triacetate membrane.

Potentiometric ion response and selectivity of asymmetric membranes

The potentiometric response characteristics of the various asymmetric cellulose acetate based ionselective membranes were evaluated and are shown in Figs. 3-5 and Table 1. As can be seen, the asymmetric ammonium-selective membranes exhibit little or no change in response slope or selectivity compared to the unmodified cellulose triacetate membrane (Fig. 3). The response slope ( $57 \mathrm{mV}$ per decade over the range from $10^{-5}$ to $10^{-1} M \mathrm{NH}_{4}^{+}$) and the high selectivity for $\mathrm{NH}_{4}^{+}$relative to several other cations (Table 1) were essentially the same as those for PVC-based membranes. ${ }^{12,16}$

Figure 4 illustrates the potentiometric response of trifluoroacetyl-p-butylbenzene (TFABB)-doped cellulose acetate membranes to carbonate and several other anions. Again, asymmetric modification (to form hydroxyl groups) had little or no effect on the response characteristics of the membrane. The re-

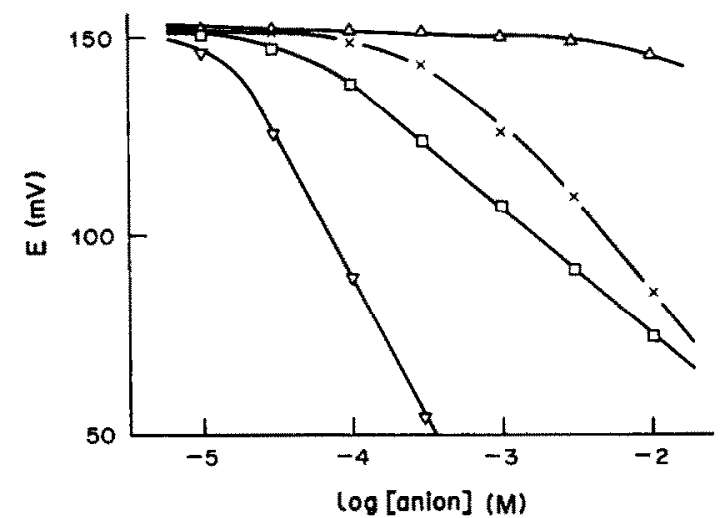

Fig. 4. Potentiometric response of a typical TFABB-doped hydroxylated asymmetric membrane to various anions in a background of $0.1 \mathrm{M}$ Tris- $\mathrm{H}_{2} \mathrm{SO}_{4}, \mathrm{pH} 8.75:(\Delta) \mathrm{Cl}^{-} ;(\times)$ $\mathrm{NO}_{3}^{-} ;(\square)$ total $\mathrm{CO}_{2}$ (predominantly carbonate and hydrogen carbonate); $(\nabla)$ salicylate.

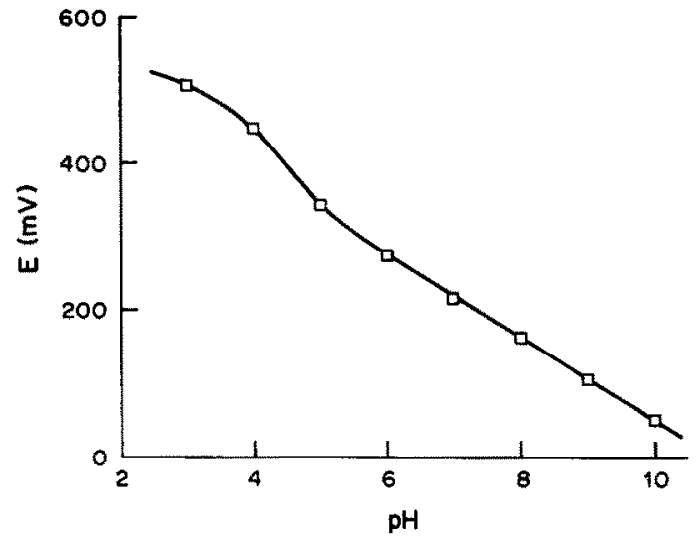

Fig. 5. Potentiometric pH response of a typical TDDAdoped hydroxylated asymmetric membrane. The $\mathrm{pH}$ was adjusted by the addition of sodium hydroxide to a buffer containing $11.4 \mathrm{~m} M$ boric acid, $6.7 \mathrm{~m} M$ citric acid, and $10.0 \mathrm{mM} \mathrm{NaH} \mathrm{PO}_{4}$, and monitored with a glass membrane electrode.

sponse slope and selectivity (or lack of it with respect to salicylate) observed are essentially the same as those found for PVC-based membranes previously reported by Greenberg and Meyerhoff. ${ }^{27}$ Similar results were obtained with proton-selective asymmetric membranes prepared with tridodecylamine as the membrane active component (see Fig. 5). Although the effect of surface hydroxyl or amine groups on the selectivity of the $\mathrm{pH}$-sensing system was not studied in detail, the fact that nearly Nernstian pH-response was observed between $\mathrm{pH} 5$ and 10 in the presence of $10 \mathrm{mM} \mathrm{Na}{ }^{+}$, suggests that the high selectivity relative to alkali-metal cations is preserved when the asymmetric membrane is used.

Response characteristics of bio-electrodes prepared with asymmetric ion-selective membranes

All three ion-selective membranes $\left(\mathrm{NH}_{4}^{+}, \mathrm{CO}_{3}^{2-}\right.$, $\mathrm{pH})$ were evaluated as sensing elements in bioelectrodes. As a model system, we chose to immobilize urease on each of the asymmetric membranes, using a variety of procedures. Urease catalyzes the reaction

$$
\left(\mathrm{NH}_{2}\right)_{2} \mathrm{CO}+2 \mathrm{H}_{2} \mathrm{O} \rightarrow 2 \mathrm{NH}_{4}^{+}+\mathrm{CO}_{2}+2 \mathrm{OH}^{-}
$$

Thus, each of the products can be detected directly or indirectly by one or other of the asymmetric ionselective membranes. In the case of the $\mathrm{CO}_{3}^{2-}$ sensor, buffering the sample solution at $\mathrm{pH} 8.4$ allows a fixed fraction of the $\mathrm{CO}_{2}$ present to be in the form of carbonate anions, detectable by the membrane doped with TFABB.

Initial experiments involved the covalent immobilization of urease on asymmetric ammoniumselective membranes. In one case, the urease was attached directly to the hydroxylated membrane by the aqueous CDI-activation method. In further studies, the urease was coupled to the surface of aminederivatized membranes by either a one- or two-step 
Table 1. Selectivity coefficients of nonactin-based membranes prepared in various matrices

\begin{tabular}{lccccccc}
\hline & \multicolumn{7}{c}{$\log k \mathrm{NH}_{4}^{+j^{*}}$} \\
\cline { 2 - 8 } Membrane matrix & $\mathrm{Li}^{+}$ & $\mathrm{Na}^{+}$ & $\mathrm{K}^{+}$ & $\mathrm{Mg}^{2+}$ & $\mathrm{Ca}^{2+}$ & $\left(\mathrm{CH}_{3}\right)_{4} \mathrm{~N}^{+}$ & $\mathrm{H}^{+}$ \\
\hline CTA & -4.7 & -2.9 & -0.9 & -3.2 & -5.0 & -3.7 & -4.3 \\
CTA-OH & -4.5 & -2.9 & -0.9 & -3.2 & -4.8 & -3.7 & -4.3 \\
CTA-NH & -4.5 & -2.9 & -0.9 & -3.2 & -4.9 & -3.7 & -4.2 \\
PVC $\dagger$ & -4.5 & -2.9 & -0.9 & -2.9 & -5.0 & -3.7 & -5.0 \\
\hline
\end{tabular}

*Determined by the separate solution method with $0.05 \mathrm{M}$ Tris- $\mathrm{HCl}$ buffer (pH 7.2) as the background electrolyte. Values are the average for several membranes. †From Ma et al. ${ }^{16}$

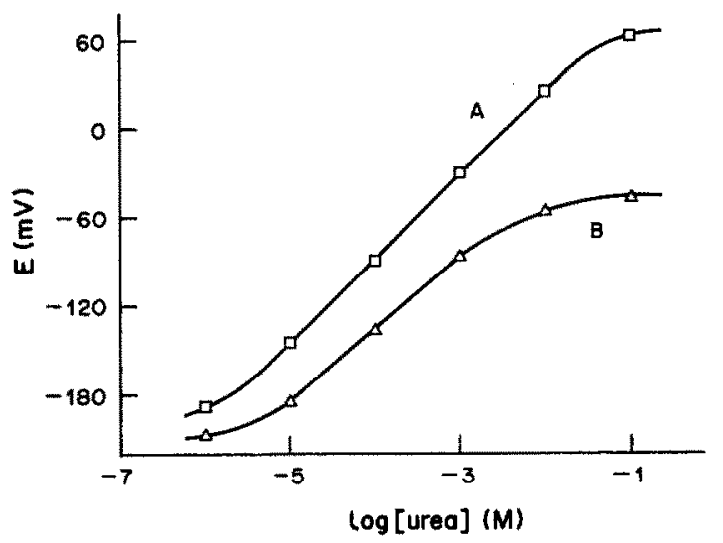

Fig. 6. Typical calibration curves for the urea electrodes prepared by using asymmetic ammonium-selective cellulose triacetate membranes: (A) urease-aminated membrane prepared by the one-step glutaraldehyde method; (B) urease-hydroxylated membrane prepared by the direct CDI activation method.

glutaraldehyde procedure. ${ }^{25}$ With the one-step glutaraldehyde method, a thin enzyme layer was formed on the surface of the membrane by crosslinking between enzymes. In all cases, however, immobilizing the enzyme had little or no effect on the response slopes and selectivity of the resulting membranes toward ammonium ions (not shown).

Typical calibration plots for the urea electrodes prepared by using asymmetric ammonium-selective membranes are shown in Fig. 6. The urease-aminated membrane prepared by the one-step glutaraldehyde method displayed a wide linear response with a slope of $57 \mathrm{mV}$ per decade in the range from $10^{-5}$ to $10^{-2} \mathrm{M}$ urea (curve A). However, the response was reduced when the urease was immobilized on the hydroxylated membrane in conjunction with direct CDIactivation (a slope of $44 \mathrm{mV}$ per decade for $10^{-5}-10^{-2} M$ urea; curve B). Analogous results were obtained for the urease-aminated membrane prepared by the two-step glutaraldehyde method (not shown). The degree of urea response is still significant, considering that the enzyme is directly attached to the surface of the membrane as a monolayer, without crosslinking networks between enzymes. It is well known that the steady-state potential of enzyme-electrodes can be affected by the amount of immobilized enzyme. ${ }^{48}$ Thus, in the case of urease immobilized directly on CDI-activated membranes, or by the two-step glutaraldehyde method involving aminated membranes, the enzyme loading levels appear to be significantly lower than those observed with a thicker layer of crosslinked urease.

Owing to an extremely fast mass transfer of species between the external bulk solution and the ionselective surface, the response of the monolayer enzyme membranes was almost instantaneous upon additions of urea to the sample (see curve $A$ in Fig. 7). The noise on such traces results from the effects of magnetic stirring, causing rapid fluctuations in the steady-state ammonium ion activities in the very thin monolayer of enzyme adjacent to the ion-selective membrane. However, more stable steady-state potentials were obtained with the thicker

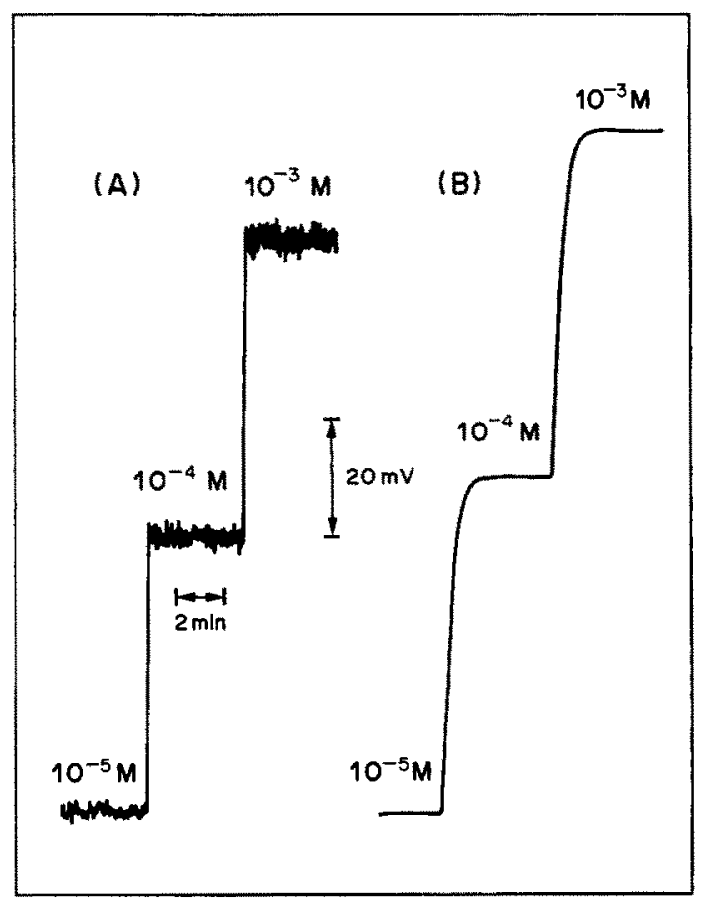

Fig. 7. Typical strip-chart recordings showing dynamic response of urea electrodes prepared by using asymmetric ammonium-selective cellulose triacetate membranes: (A) urease-aminated membrane prepared by the one-step glutaraldehyde method; (B) urease-hydroxylated membrane prepared by the direct CDI- activation method. 


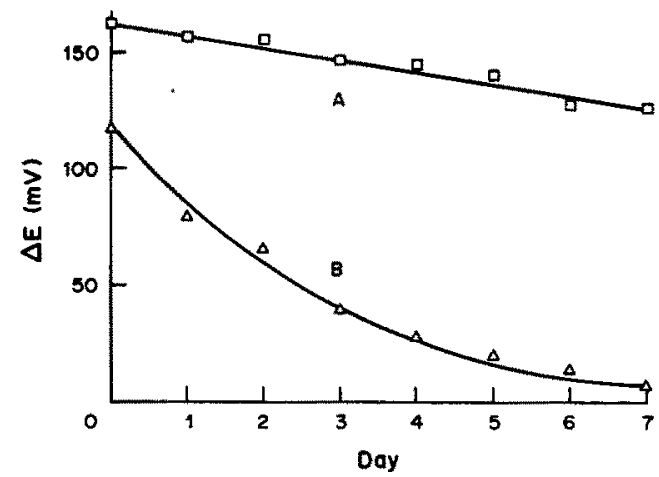

Fig. 8. Stability of urease immobilized on the hydroxylated ammonium-selective cellulose triacetate membranes: (A) covalent attachment with direct CDI-activation; (B) nonspecific adsorption (without $\mathrm{CDI}$ - activation). The absolute potential changes towards $10^{-3} \mathrm{M}$ urea in $0.05 \mathrm{M}$ Tris-

$\mathrm{HCl}, \mathrm{pH} 7.2$ were recorded over a period of 1 week.

one-step glutaraldehyde crosslinked urease membrane (curve B in Fig. 7). The response of this electrode was still faster than reported previously for similar devices prepared with polyacrylamide-encapsulated films of urease coating ammonium-selective membranes. ${ }^{26}$ Indeed, the $98 \%$ steady-state potential was reached in $45 \mathrm{sec}$ for a concentration change from $10^{-4}$ to $10^{-3} \mathrm{M}$ urea.

The stability of immobilized urease was also evaluated for each covalent attachment procedure. The crosslinked enzyme layer on the aminated membrane still remained active after one month, and during this period, only a slight change in the response slope was observed. On the other hand, the crosslinked enzyme layer on a blank membrane (i.e., urease immobilized by the one-step glutaraldehyde procedure on a hydrolyzed membrane or a nonasymmetric membrane) was easily removed by brief washing with buffer (poor adhesion). The stability of urease attached to the hydrolyzed membrane by the direct $\mathrm{CDI}$ method was

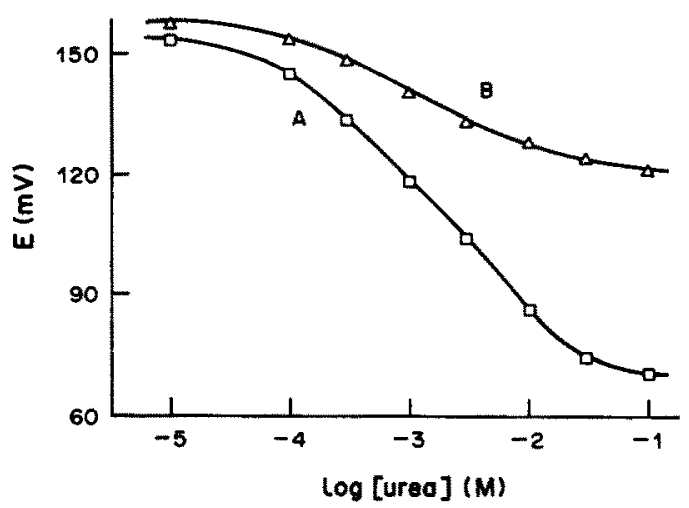

Fig. 9. Typical calibration curves for the urea electrodes prepared by using asymmetric carbonate-selective cellulose triacetate membranes: $(A)$ urease-aminated membrane prepared by the one-step glutaraldehyde method; (B) urease-hydroxylated membrane prepared by the direct CDI-activation method. Potential measurements were made in $0.1 M$ Tris- $\mathrm{H}_{2} \mathrm{SO}_{4}, \mathrm{pH} 8.75$. also checked over a period of 1 week by determining the absolute potential responses to $10^{-3} \mathrm{M}$ urea (Fig. 8). The response of the membrane (curve A) was not substantially reduced after a week, whereas the response of the blank membrane (i.e., urease applied to a hydrolyzed membrane without CDI-activation) sharply decreased (curve B). The response in the latter case results from nonspecifically adsorbed urease. It should also be mentioned that the degree of nonspecific adsorption of urease was much greater (approximately 5 times) on nonasymmetric plasticized CTA membranes.

Urea-selective bio-electrodes were also prepared by immobilizing urease on carbonate-selective asymmetric membranes either by the one-step glutaraldehyde method for an aminated membrane (Fig. 9; curve A) or by the direct CDI method for a hydrolyzed membrane (Fig. 9; curve B), The response slopes of each membrane were $-29 \mathrm{mV}$ (curve A) and $-14 \mathrm{mV}$ (curve B) per decade over the range from $10^{-4}$ to $10^{-2} M$ urea, respectively. Again, the lower slope for the membrane obtained by the direct CDI immobilization method suggests a decreased level of enzyme loading compared to the crosslinked enzyme membranes. In the case of all bio-electrodes prepared with the carbonate sensor, the response time of the base membranes toward carbonate ions was increased by enzyme immobilization. For all types of enzyme-linked carbonate membranes, the response time $(98 \%)$ was found to be $55 \mathrm{sec}$ for a concentration change from $10^{-3}$ to $10^{-2} \mathrm{M}$ urea.

Finally, urease was immobilized on the surface of tridodecylamine-based $\mathrm{H}^{+}$-selective asymmetric membranes. As with other pH-based enzyme electrodes, ${ }^{27}$ the calibration curves for urea were obtained in a weakly buffered background electrolyte solution $(0.001 M$ Tris- $\mathrm{HCl} / 0.1 M \mathrm{NaCl}, \mathrm{pH} 7.0)$, and are shown in Fig. 10. Substantial $\mathrm{pH}$ changes were observed at the surface of the crosslinked enzyme

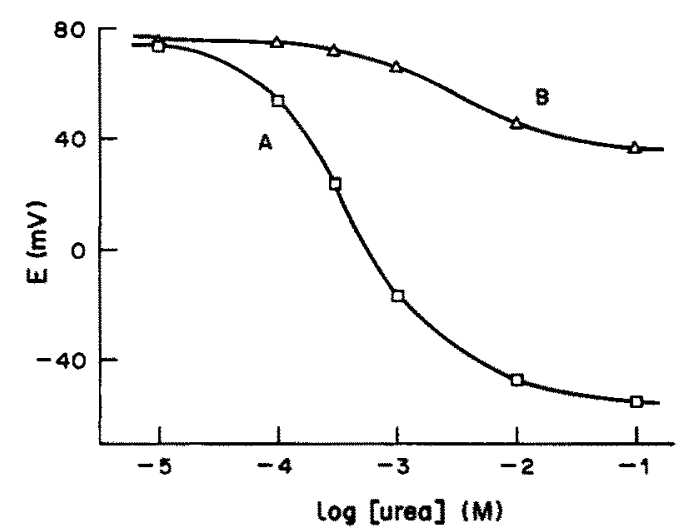

Fig. 10. Typical calibration curves for the urea electrodes prepared by using aminated $\mathrm{H}^{+}$-selective cellulose triacetate membranes. Urease was attached by one-step glutaraldehyde method (curve A) or two-step glutaraldehyde method (curve B). Potential measurements were made in $0.001 M$ Tris- $\mathrm{HCl} / 0.1 M \mathrm{NaCl}, \mathrm{pH} 7.0$. 
layer membrane in the range from $10^{-5}$ to $10^{-2} \mathrm{M}$ urea (total change $125 \mathrm{mV}$ ), whereas bio-electrodes prepared with monolayer enzyme coverage exhibited relatively poor response owing to the rapid transfer of $\mathrm{H}^{+}$out of the ultrathin enzyme-layer (i.e., it is not possible to sustain a steady-state $\mathrm{pH}$ change adjacent to the $\mathrm{pH}$-sensing membrane.)

In summary, we have described the preparation and performance of a new type of asymmetric ionselective membrane based on cellulose acetate. The potentiometric response of these membranes toward ions is essentially the same as that of conventional plasticized PVC membranes. More importantly, the hydroxylated side of the membranes can be used to immobilize bioreagents covalently by a variety of reaction schemes without affecting the ionic response or selectivity of the membranes. While immobilization of the enzyme urease in thin crosslinked films results in urea-selective bio-electrodes with a greater degree of enzyme loading, and thus larger urea responses (regardless of the base ion-sensor), the ability to immobilize thin monolayers of biological reagents on the surfaces of functional ISEs by the direct $\mathrm{CDI}$ method may prove extremely valuable in the design of other types of bio-electrode systems; e.g., disposable immunoelectrodes, etc. Work in this direction is in progress.

Acknowledgements - The authors wish to thank Mr. Glen H. Bolling for assistance in taking scanning electron micrographs. This work was partially supported by the National Science Foundation (CHE-8506695) and the National Institutes of Health (GM-28882).

\section{REFERENCES}

1. M. A. Arnold, Ion-Selective Electrode Rev., 1986, 8, 85 .

2. G. G. Guilbault and J. M. Kauffmann, Biotechnol. Appl. Biochem., 1987, 9, 95.

3. M. Mascini and G. G. Guilbault, Biosensors, 1986, 2, 147.

4. R. K. Kobos, in Ion-Selective Electrodes in Analytical
Chemistry, H. Freiser (ed.), Vol. II, Chap. 1. Plenum Press, New York, 1980.

5. G. G. Guilbault. Handbook of Enzymatic Methods of Analysis, Chap. 5. Dekker, New York, 1976.

6. P. W. Carr and L. D. Bowers, Immobilized Enzymes in Analytical and Clinical Chemistry, Chap. 5. Wiley-Interscience, New York, 1980.

7. G. G. Guilbault and J. G. Montalvo, $J, A m$. Chem. Soc., 1970, 92, 2533.

8. J. E. Brady and P. W. Carr, Anal. Chem., 1980, 52, 977.

9. J. D. R. Thomas, Anal. Chim. Acta, 1986, 180, 289.

10. P. Oggenfuss, W. E. Morf, U. Oesch, D. Ammann, E. Pretsch and W. Simon, ibid., 1986, 180, 299.

11. W. Simon, E. Pretsch, W. E. Morf, D. Ammann, U. Oesch and O. Dinten, Analyst, 1984, 109, 207.

12. D. Ammann, W. E. Morf, P. Anker, P. C. Meier, E. Pretsch and W. Simon, Ion-Selective Electrode Rev., $1983,5,3$.

13. D. Ammann, Ion-Selective Microelectrodes; Principles, Design, and Application, Chap. 4. Springer-Verlag, Berlin, 1986.

14. T. Satchwill and D. J. Harrison, J. Electroanal. Chem, $1986,202,75$.

15. E. Linder, E. Gráf, Z. Niegreisz, K. Tóth, E. Pungor and R. P. Buck, Anal. Chem., 1988, 60, 295.

16. S. C. Ma, N. A. Chaniotakis and M. E. Meyerhoff, ibid., 1988, 60, 2293.

17. S. J. Pace, Eur. Pat. Appl, EP 138150, 1985: Chem. Abstr., 1985, 103, 19426k, 1985.

18. J. Anzai, M. Shimada, T. Osa and C. Chen, Bull. Chem. Soc. Japan, 1987, 60, 4133.

19. T. Okada, H. Sugihara and K. Hiratani, Anal. Chim. Acta, 1986, 186, 307.

20. G. S. Bethell, J. S. Ayers, W.S. Hancock and M. T. W. Hearn, J. Biol. Chem., 1979, 254, 2572.

21. M. T. W. Hearn, G. S. Bethell, J. S. Ayers and W. S. Hancock, J. Chromatog., 1979, 185, 463.

22. G. S. Bethell, J. S. Ayers, M. T. W. Hearn and W. S. Hancock, ibid., 1981, 219, 361.

23. P. Cuatrecasas, $J$. Biol. Chem., 1970, 245, 3059.

24. J. A. Greenberg and M. E. Meyerhof, Anal. Chim. Acta, 1982, 141, 57.

25. J. F. Kennedy, B. Kalogerakis and J. M. S. Cabral, Enzyme Microb. Technol., 1984, 6, 127.

26. G. G. Guilbault and G. Nagy, Anal. Chem., 1973, 45, 417.

27. R. M. Ianniello and A. M. Yacynych, Anal. Chim. Acta, 1983, 146, 249. 